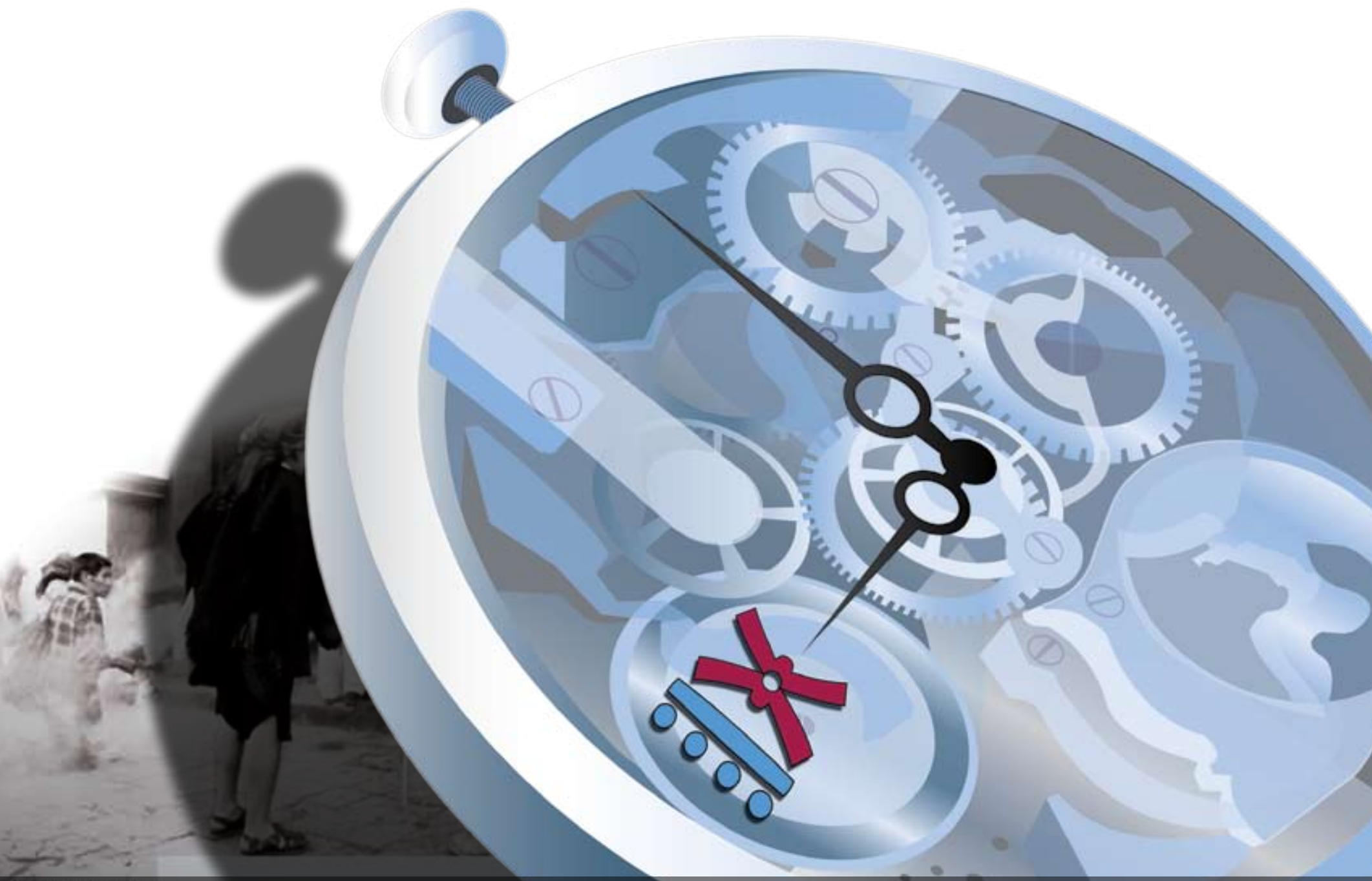

$9^{\circ}$ C O N G R E S O 2. CENTROAMERICANO DE H IS TO R I A
Universidad de Costa Rica

ISSN 1409- 469X

Fecha de recepción: 15 de mayo 2008 Fecha de aceptación: 30 de mayo 2008

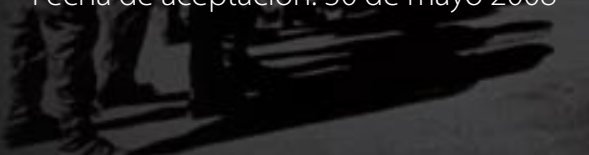

Mandatos arquetipales y símbolos: universidad venezolana del siglo XIX

Miembros del Consejo Editorial:

Dr. Ronny Viales, Dr. Juan José Marín

Editores Técnicos:

Allan Fonseca, Andrés Cruz, Gabriela Soto

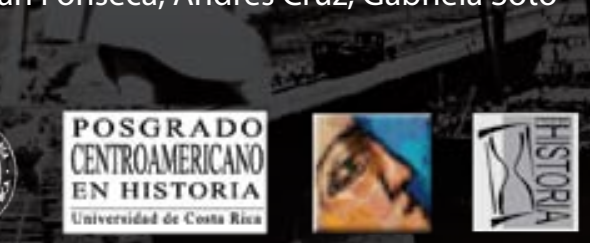


Indexaciones: Repositorio de Revistas UCR, DIALNET, Latindex, REDALYC Directorio y recolector de recursos digitales del Ministerio de Cultura de España, Directory of Open Access Journals. Diálogos Revista Electrónica de Historia ISSN 1409-469X. Número especial 2008. Dirección web: http://historia.fcs.ucr.ac.cr/dialogos.htm

\title{
Mandatos arquetipales y símbolos: universidad venezolana del siglo XIX
}

\author{
Carlos R. Villamizar
}

Dr. en Educación de la Universidad Pedagógica Experimental Libertador (UPEL), miembro activo del ranking nacional de investigadores del Ministerio de Ciencia y Tecnología, miembro del Núcleo de Investigación Educa (Educación, Cultura y Cambio), profesor asociado de la UPEL, facilitador de cursos en Métodos de la Universidad de la Fuerza Armada y la Universidad del Táchira. Correo electrónico migdav@

cantv.net. 


\section{Introducción}

El presente texto tiene varias lecturas posibles. La primera de ellas, se puede realizar en términos que sugiera la interrogante sobre el Porqué de los mandatos arquetipales. La idea de la concepción saber-ciencia en la universidad venezolana del siglo XIX, surge desde una postura un tanto psicoanalítica; a decir a la manera de Carl Jung, busca esas tramas, esas dudosas capacidades de libertad, de autodeterminación, de trascendencia y creatividad, en favor de estructuras profundas e inconscientes, "pensamientos oscurecidos temporalmente, impresiones e imágenes que, a pesar de haberse perdido, continúan influyendo en nuestra mente consciente”1 enmascaradas y representacionales de una realidad que vivió intensas luchas con el conocimiento.

Por consiguiente busca la oposición ante el atomismo que promueve reducir las totalidades a unas asociaciones entre elementos previos ${ }^{2}$ y ante la creencia de que todo lo que se da en este siglo en materia de conocimiento, no es más que lo que está cortado por la égida de un saber que en primera instancia fue para la universidad venezolana escolástico, más tarde ilustrado y posteriormente positivista, pero que muy probablemente estuvo signada por símbolos heredados o "ideas primordiales"3, marcadas como estructuras innatas en el inconsciente colectivo de los individuos actores de la universidad venezolana de este siglo.

Es así como la búsqueda de esa verdadera esencia desde el ángulo simbólico, quiere examinar en esa mediedad entre el saber y la ciencia. Pero para ello, parte de la definición de arquetipo que más se aproxima a esa mediedad aristotélica entre saber y ciencia. Así el arquetipo representa esencialmente un contenido inconsistente, que al concientizarse y ser percibido cambia de acuerdo con cada conciencia individual en que surge como "remanentes arcaicos"4. Así mismo el saber se define como aquella estructura amplia y abarcante, o como esa totalidad donde se inscribe el campo de la ciencia propia, pero también ese saber que se da a través de las representaciones del mundo, del símbolo y del significante en las expresiones de Morín, o como “aquella acción que transforma al sujeto para que éste transforme al mundo”5.

1 1. Carl Gustav Jung. “Acercamiento al inconsciente”, en El Hombre y sus Símbolos, ed Carl Gustav Jung (Barcelona, España: Biblioteca Universal Contemporánea/ Caralt, 1997), 29

2 2. Jean Piaget. El estructuralismo (Barcelona, España: Oikos-Tau, 1980), 8

3 3. Carl Gustav Jung. Arquetipos e inconsciente colectivo (Buenos Aires, Argentina: Paidós, 1970), 10

4 4. Carl Gustav Jung, Acercamiento al inconsciente, 65

5 5. Jacky Beillerot, Claudine Blanchard-Laville y Nicole Mosconi. Saber y relación con el Saber (Buenos 
Por consiguiente ese concepto de saber tiene que ver con aquel que designa la búsqueda de ese algo estático y oculto, pero a la vez dinámico y dispuesto dentro del complejo de fenómenos de la sociedad del siglo XIX y en especial al interno de los procesos de la universidad venezolana, sin obviar su entorno, pero sin dejar de lado la idea de formas específicamente configuradas que se han transmitido por ciertos periodos de tiempo.

El concepto de ciencia, aquel que no es sólo epistemológico, sino tanto más un problema ontológico, es decir, ese concepto que indudablemente da pie con la crisis del conocimiento como las ocurridas en las transiciones escolástica-ilustración o ilustración-positivismo, que afecta de algún modo el concepto de ser y de realidad subyacente a la actividad científica y que "al identificarla verdad con la objetividad, achica el saber" ${ }^{6}$ y que se involucra en la crisis de la sociedad y en la inconsciencia sobre los problemas sociales que la ciencia del siglo XIX olvida. Así el problema de la ciencia que en la concepción Foucaultiana forma parte del amplio campo del saber, ha de ser analizado y solventado en relación con el "mundo de la vida” de Husserl”, de donde toda ciencia emerge y en donde todo científico actúa; lo cual involucra no sólo aspectos referentes a la teoría de la ciencia, sino también sobre otros concernientes, a la ontología y al mismo problema ético.

La ciencia vista para una universidad en constante transformación, tal vez signada por los problemas políticos de la época, como el nacimiento de la república y los momentos claves de reacomodamiento de un país. Así la visión que se tiene aun hoy, es la que comúnmente se maneja acerca del siglo XIX, fundada en una serie de desordenadas y cruentas guerras, depresiones económicas, políticas e inclusive culturales que lo identifican como el de la "barbarie". Entonces imaginar que existió algo de ciencia en ese período tan convulsionado, es un atrevimiento, más aún cuando casi a lo largo de todo el siglo, sólo existían dos instituciones universitarias de corte escolástico como: La Universidad de Caracas, que con la reforma educativa de 1827 pasó a ser la Universidad Central de Venezuela y la Universidad de Mérida, que a partir de 1832 se consolida estatutariamente y luego pasa a convertirse en Universidad de los Andes. Pero también y quizá con mayor fuerza con las crisis de los paradigmas científicos, que sacudían con rudeza el "establishment" del conocimiento, en el cual a partir de 1870, da un vuelco de 180 grados a las estructuras del saber y la ciencia imperante que tuvo su medida de influencia en nuestro país.

Aires, Argentina: Paidós, 1998), 10

6 6. José M. G. Gómez-Heras. El a priori del mundo de la vida. (Barcelona, España: Anthropos, 1989), 135

7 7. ibid, 220 
Otra lectura que se le puede adicionar a este texto, se refiere en los términos de la pregunta ¿Porqué en la universidad venezolana del siglo XIX? La Universidad venezolana entre fines del XVIII y comienzos del XIX (hasta 1830), es una institución que nace bajo la influencia de su homólogo de la civilización occidental europea, ésta última con una trayectoria de casi mil años y con una estructura organizativa de carácter feudal. Esta universidad aún mantiene rasgos importantes de la institución colonial, escolástica y silogística, pero ya a mediados del siglo XVIII y temprano en el siglo XIX, es penetrada por las ideas racionalistas de la ilustración europea, como es el caso de la Universidad de Caracas, que gracias al Dr. Baltazar de los Reyes Marrero en 1788, quien inició el cambio dentro de la cátedra de filosofía dominada por el trienio filosófico ${ }^{8}$. Es una cuestión relevante del nuevo pensamiento en cuanto a la enseñanza universitaria, era la enseñanza de las matemáticas, porque el fenómeno físico al ser estudiado requiere de cuantificación ${ }^{9}$; no obstante se puede afirmar, que ya ubicados en el siglo XIX, las filosofías europeas; el racionalismo o la ilustración y luego el positivismo, es aceptado como una valor declarado, pero no entra a formar parte activa de nuestra cultura, por una parte determinado por un inconsciente colectivo que domina las esferas sociales de los individuos que provienen de una cultura dominada por arquetipos religiosos y simbolismos provenientes de la España religiosa y escolástica, y no tenía porqué ser de otra manera, pues no había una causa social y económica que justificara el cambio al respecto ${ }^{10}$. Entonces, es sólo en la universidad donde se siente verdaderamente su influencia y por consiguiente es necesario revisar en su interior éste fenómeno, para ver como esa concepción muy particular de la relación saber-ciencia se mueve en función de lo paradigmático y lo ideológico, de la producción de ciencia y tecnología e innovación, y en general de la relación saber-poder.

8 8. Guillermo Luque. Historia oral. Momentos de la educación y la pedagogía venezolana (entrevista a Gustavo Adolfo Ruiz) (Caracas, Venezuela: Faces/UCV, 2001), 59

9 9. ibid, 60

10 10. José Alberto Alcalde A. La educación en Hispanoamérica. Reflexiones para el debate (Mérida, Venezuela: Consejo de publicaciones de la Universidad de los Andes, 2002), 25 


\section{Pluralización del imaginario central}

Una vez lograda la independencia, se iniciaron lentos cambios que fueron reemplazando el modelo escolástico y eclesiástico, por la llamada universidad republicana, más dinámica, tolerante y aparentemente científica; ya en 1827, el Estatuto Bolivariano incorpora nuevas cátedras y laboratorios, sobre todo en las áreas de matemáticas, física y ciencias naturales ${ }^{11}$. Con esto se da en la universidad un gran paso en la implementación de la ciencia experimental proveniente de los centros intelectuales de Europa, por acción del Dr. José María Vargas; quien impulsa un proceso modernizante de la institución ante un público que aún vive una pasmosa ideología conservadora. Se eliminaron o redujeron las restricciones raciales, económicas y de tipo religioso y se suprime el latín como lengua oficial de enseñanza, no obstante el siglo XIX como escenario de reformas de la universidad pasa por despojarse de su vestimenta colonial, expresión del oscurantismo, de la escolástica y del clericalismo y la construcción de una universidad que respondía a la condición de institución nacional; pero estos ideales para transformarla, responden primigeniamente a la idea de fuerza de la modernidad, fueron frustrados casi al nacer; trastocándose en simple modernización, porque la sociedad se hizo cada vez menos moderna, menos racional, desde el mismo momento en que los nuevos ideales liberales se plegaron a la servidumbre de los nuevos patrones de poder y de sociedad que se extendían en Europa y luego en E.E.U. $\mathrm{U}^{12}$. Es un choque entre una cultura cuyo saber dominante gira en torno a la creencia divina y popularmente en la multiplicidad de cosmovisiones, propio de la cotidianidad de un pueblo que empezaba a pensar que podía ser otro y no el que los españoles católicos a ultranza, o ilustrados moderados les habían hecho saber que eran.

Es la representación colectiva de un saber amplio, pues entra también en el terreno de lo espiritual propio de la Venezuela de inicios del siglo XIX, donde la religión es la protorepresentación colectiva, por excelencia y su argumento central es la presentificación de un "imaginario social radical, Dios o maná-totémico"13 , portador de significaciones sociales y cuyas interpretaciones del mundo giran en torno a lo sagrado y lo profano que delimitan y configuran

11 11. Idelfonso Leal. La Universidad de Caracas en los años de Bolívar (1783-1830) (Caracas, Venezuela: Ediciones del rectorado UCV, 1983), 55

12 12. Aníbal Quijano. "Modernidad, identidad y utopía en América Latina”, en Modernidad y Universalismo, ed Edgardo Lander (Caracas, Venezuela: UNESCO/UCV/Nueva Sociedad, 1991) ,220

13 13. Berian Josetxo. Representaciones Colectivas y Proyecto de Modernidad (Barcelona, España: Anthropos 1990),18 
el conocimiento de "lo real", del espacio y del tiempo, de la causalidad y de la verdad y que se convierten en conciencia social.

Pero en contraparte a esta realidad, con la llegada de la ciencia experimental y de la modernidad ocurre un proceso de desencantamiento o descentramiento y "racionalización" de las creencias de la sociedad venezolana de fines del XVIII y comienzos del XIX. La ciencia pasa a ser un dispositivo cognitivo al servicio de esta racionalización, de la producción tecnológica y de la reproducción de la fuerza de trabajo. Ya no existe al interno de la universidad un simbolismo "neutro" o bien totalmente adecuado al funcionamiento de los procesos reales, sino que la lógica interna de lo simbólico-cultural se incorpora en las instituciones y surgen nuevas formaciones ideológicas, paradigmáticas y discursivas en el concepto de ciencia, de moral, de arte y de la misma religión.

Así nos encontramos en una sociedad donde sus instituciones como la universidad y al interno de ellas, ocurren cambios importantes y es a partir de 1830, con la ocurrencia de cosmovisiones políticas y el adentramiento en una república proveniente de un proceso "Balkanizante". La Universidad Central de Venezuela experimenta cierta metamorfosis en la que se escinden, se autonomizan esferas culturales de valor, como el arte/literatura, ciencia/ tecnología y moral/derecho, entonces ella, irradia una multiplicidad de representaciones y se pluralizan las estructuras de conciencia.

Ya para 1832, se incorpora tímidamente la Universidad de Mérida, en esta nueva desmagicización de la ciencia y la filosofía, sin embargo a pesar de mantener estructuras propias del mundo anterior (instituido de significados y simbolismos religiosos) es para 1854 cuando a partir de los estudios de medicina, se incorpora este paradigma del descentramiento de las cosmovisiones; el cual se consolida con la "llegada" del movimiento positivista y el movimiento evolucionista que se da a partir de 1864, dando inicio así a un saber que prevalece hasta mediados del siglo XX.

\section{Positivismo y evolucionismo}

La U.C.V. y la Universidad de Mérida para 1870 ya están imbuidas en una nueva representación del saber y la ciencia, se produce un fenómeno de pluralización de estructuras de conciencia que tienen su fundamento en un paralelo en la nueva fundamentación moderna del 
conocimiento. En él se despliega un pluralismo epistemológico relacionado con las diferentes narrativas o formaciones discursivas, dependiendo de las diferentes funciones de los juegos pragmáticos de lenguaje que se impone por la acción de la moda del positivismo liderado por Comte y otra corriente un tanto disímil a ésta liderada por el evolucionismo de Spencer, lo que causa una hecatombe del saber cotidiano, lo hace casi invisible, y donde ya es casi seguro hablar de que saber es sinónimo de ciencia y conocimiento. Pero en estos momentos podemos decir que tenemos a la vista algunos arquetipos con sus símbolos: el arquetipo de principios de siglo; la universidad escolástica hasta fines del 30, luego la prevalescencia del mismo en los Estatutos de la Universidad de Caracas con respecto a los grados académicos, las disciplinas escolásticas y las normas internas de la institución que de igual forma se manifiesta en los estatutos de la universidad de Mérida en el año 1832; luego llega el paradigma experimentalista que se ha anidado en la mente "antes" de los liberadores de la patria y se replica en la intelectualidad de la universidad; posteriormente surge el positivismo pero al contrario de Europa ,éste tiene su particularidad en la idea de que de él se origina la ciencia ,sin obviar la influencia religiosa y escolástica sobre los intelectuales y el colectivo que marcan un "nuevo" paradigma educativo que se reflejó en el siglo XX, es el de la "Escuela Nueva".

Josetxo ${ }^{14}$, detecta en Weber cómo se institucionalizan en la modernidad tres complejos de racionalidad postradicional o post sacral: que perfectamente se exteriorizan en la universidad venezolana del siglo XIX y por supuesto invade los círculos culturales, económicos, políticos y en general de la sociedad de las grandes ciudades, más en contacto con la influencia Europea, sobre todo la francesa y la inglesa. Esos complejos se manifiestan en la producción de formaciones discursivas: primero la ciencia, con el establecimiento de una empresa científica de acuerdo a estándares provenientes de las sucesivas visitas de extranjeros que vienen a hacer investigación, sólo por el hecho de ganar prestigio en la explotación del "nuevo mundo”, dejando a cambio muy poco: porque nuestra cultura asimila muy lentamente sus posibles enseñanzas; segundo, la moral y el derecho donde se da el tratamiento intelectual profesional de cuestiones de ética, teoría política y jurisprudencia en las escuelas de derecho en conjunción con el sistema legal establecido; en tercer lugar el arte, con la institucionalización de una empresa artística desvinculada de motivos cúltico-eclesiásticos y cortesano-patronales. Así a la manera de Foucault, esto no es más que la emergencia de nuevas formas de coerción y técnicas disciplinarias para la subordinación y el

14 14. Ibid, 19 
control de los cuerpos,” un sistema de poder que no está tan sólo en las instancias de la censura, sino que penetra de un modo profundo, muy sutilmente, en toda la red de la sociedad"15

En este sentido, a partir de la enseñanza de los postulados del positivismo que inició Rafael Villavicencio y Vicente Marcano entre otros, o del evolucionismo que promovió Adolfo Ernst en las aulas de la U.C.V. Es a partir de allí que comienza a dársele otro sentido a la "verdad", al desvelamiento de la racionalización social caracterizado por una lógica teleológica, al universo dado por supuesto de la actividad diaria. Es la "conciencia colectiva", la "memoria colectiva" que proporciona los esquemas de coexistencia de la vida social, los criterios de la representación simbólica y las maneras de hacer cosas. Pero estas maneras toman otro rumbo, donde lenguaje y cultura son dos elementos que se redefinen de acuerdo a este nuevo modo de "pensar" y "hacer". Es a lo sumo una metamorfosis conceptual que en este siglo ya ha tenido varias. Una por la acción de un imaginario radical central (Dios) y el miedo mítico al poder de la naturaleza, otro por la acción de la razón instrumental y la supuesta libertad donde el poder reside en los hombres; la tercera por la voz del orden, el progreso y la ciencia, que van a conformar lo que en el mundo se ha dado en llamar "Estado Moderno", pero que se expresan en un saber de cuerpos heteróclitos y eclécticos de sistemas de ideas como el materialismo, el experimentalismo, el evolucionismo, entre otros elementos ideológicos.

La llegada del "boom positivista" y del "boom evolucionista" fue tomada en forma conjunta para nutrir los diversos proyectos de constitución de una cultura, que más tarde se traduce, en una "cultura nacional" a decir de Marta de la Vega ${ }^{16}$. Convirtiéndose en una filosofía para la praxis científica, es decir, en la generadora de la ciencia. Así podemos concluir que la concepción saberciencia en la universidad venezolana del siglo XIX, no es más que el aniquilamiento casi total de ese saber amplio que fue legado de nuestros ancestros con sus trazas arquetípicas de cristianismo y cosmovisión y que pudo haber sido la respuesta a nuestros propios problemas en favor de estructuras pragmáticas y utilitaristas provenientes de la imposición del "mundo civilizado", pero que a lo largo del tiempo se ha convertido en el "verdadero conocimiento", y del cual como país actual, busca alcanzar esos niveles que lo ubiquen satisfactoriamente en los índices

15 15. Michel Foucault. Un diálogo sobre el poder y otras conversaciones (Madrid, España: Alianza/ Materiales, 2001),25

16 16. Marta de la Vega. Evolucionismo versus positivismo. (Caracas, Venezuela: Monte Ávila Editores, 1998), 13 
de competitividad que aun no se logra con universidades más modernas y con instituciones a las cuales se les dedica un presupuesto para hacer ciencia y tecnología. Es a mi parecer, el letargo del que no pudimos despertar una vez que nos liberamos de las ataduras del coloniaje español y en el que entramos atados de manos al nuevo saber, sin asimilarlo a nuestra cotidianidad y sin ubicarlo en niveles de autoconciencia, sólo esperando consumir la moda que nos llega.

\section{Conclusiones}

En un momento preciso de nuestra historia cercana, finales del siglo XIX y primeros del siglo $\mathrm{XX}$, cuando las ciencias naturales exactas, a través del positivismo, del evolucionismo y del experimentalismo, pretendían imponer sus métodos a las ciencias de la cultura en la universidad venezolana; la fenomenología se convierte en una revuelta que trata de comprender qué ocurrió y qué trascendencia ha tenido en nuestra sociedad, el hecho de asimilar una cultura, un paradigma de la ciencia, sin evaluar sus efectos y sin siquiera "revisar" sus intencionalidades y sus sentidos. Hoy los efectos de esa influencia aún perduran en otras concepciones del saber como el postpositivismo, o las filosofías analíticas de corte logicísta, que marcan el camino de la acción en la producción de ciencia y tecnología o en el proceso de investigación que se produce al interno de la institución universitaria venezolana o en los sistemas de producción de ciencia, donde se relega al olvido y al anonimato aquellos saberes “alternativos” y otras subjetividades. Así lo fenoménico requiere ser un análisis de ese mundo, en vistas de posibilitar una comprensión del sentido de la cultura actual. La explicación del mundo objetivo a partir de una subjetividad trascendental para comprender y "rediseñar" esos efectos perversos o no -que han dado al trastecon la poca cultura científica actual que nos afecta en nuestro modo en la producción de un saber y una ciencia que nos conduzca por el camino de la liberación, o que nos haga ser más originales en ese contexto apabullante de la infinitud del conocimiento.

\section{Referencias}

- Alcalde, A. (2002). La educación en Hispanoamérica. Reflexiones para el debate. Mérida, Venezuela: Consejo de publicaciones Ula.

- Beillerot, J y Laville, C. (1998). Saber y relación con el saber. Buenos Aires, Argentina: paidós. 
- De la Vega, M. (1998. Evolucionismo versus positivismo. Caracas, Venezuela: Monte Ávila.

- Foucault, M. (2001) Un diálogo sobre el poder y otras conversaciones. Madrid, España:Alianza/Materiales

- Gómez-Heras, J.(1989). El a priori del mundo de la vida. Fundamentación fenomenológica de una ética de la ciencia y de la técnica. Barcelona, España: Anthropos.

- Josetxo, B. (1990). Representaciones colectivas y proyecto de modernidad. Barcelona, España: Anthropos.

- Jung, C. (1970). Arquetipos e inconsistente colectivo. Buenos Aires, Argentina:

Paidós.

- Jung, C. (1997) “Acercamiento al inconsciente “en. El hombre y sus símbolos. Barcelona, España: Biblioteca Universal Contemporánea/Caralt

- Luque, G. (2001). Historia oral. Momentos de la educación y la pedagogía venezolana (entrevista a Gustavo Adolfo Ruiz). Caracas, Venezuela: Faces/UCV.

- $\quad$ Piaget, J. (1980). El estructuralismo. Barcelona, España: Oikos-tau.

- Quijano, A. (1991). “Modernidad, identidad y utopía en América Latina”, en Lander. E. Modernidad y universalismo. Caracas, Venezuela: UNESCO/UCV/Nueva sociedad.

- Leal, I (1983).La universidad de Caracas en los años de Bolivar(1783-1830). Caracas, Venezuela: Ediciones del Rectorado UCV 